\title{
Cardiac Risk Assessment in American South Asian Population
}

\author{
Rohan Trivedi, Sunil Pathak, Nikhil Iyengar, Alison C Essary and Priya Radhakrishnan* \\ Department of Internal Medicine, HonorHealth Medical Group, USA
}

*Corresponding author: Priya Radhakrishnan, Department of Internal Medicine, HonorHealth Medical Group, USA.

Received Date: November 23, 2019

Published Date: December 02, 2019

\section{Introduction}

Cardiovascular disease (CVD) includes four major areas: coronary heart disease, cerebrovascular disease, peripheral artery disease and aortic atherosclerosis, and thoracic or abdominal aortic aneurysm. CVD is the number one cause of death globally. An estimated 17.9 million people died from CVD in 2016, representing $31 \%$ of all global deaths [1]. CVDs are also the leading cause of death, hospitalizations and medical costs in United States [2,3]. An estimated $80 \%$ of CVDs are preventable [4]. Cardiac risk assessment is the cornerstone for aiding appropriate delivery of preventive therapy, and yet there are few risk models applicable to minority U.S. populations, this is particularly applicable to the South Asian sub-population.

\section{Epidemiology}

Asian Americans are the fastest-growing major racial or ethnic group in the United States. Six origin groups - Chinese, Indian, Filipino, Vietnamese, Korean and Japanese - account for $85 \%$ of all Asian Americans as of 2015 [5]. According to the U.S. Census bureau, the total population of Asian Americans grew by 43 percent from 10.2 million in 2000 to 14.7 million in 2010, which constituted the largest increase of any major racial group during that period [6]. Furthermore, South Asian Americans Living Together (SAALT) estimates up to 5.4million South Asian Americans lived in the United States in 2017 [7]. Heart disease is the leading cause of death in the Asian American population, but disparities exist in terms of the course of diagnosis and treatment. Asian Americans have higher mortality rates and die at an earlier age from stroke compared to White Americans; and CVD, especially coronary heart disease, tends to occur earlier in life and in a higher percentage of the population in Asian Indians than in other ethnic groups. This data may, in part, be linked to the lack of an evidence-based screening tool designed specifically for Asian American [8].The 2019 ACC/AHA guideline on the primary prevention of cardiovascular disease suggests using the race and sex specific Pooled Cohort Equation for cardiac risk assessment but does note this is best validated for non-Hispanic Whites and non-Hispanic blacks [9]. The risk models tend to either overestimate or underestimate risk in Asian populations [10-14]. Even among Asian populations, risks are higher in South Asians $[13,14]$. Varying estimates note Asian Indians to have up to 4 times higher risk of coronary artery disease than the average American population, and 20 times higher than Japanese population [15-18].

\section{Risk Factors}

Studies have shown that Asian Indians had similar overall body fat percentage at significantly lower overall Body Mass index (BMI) compared to Caucasian populations (BMI of $24 \mathrm{~kg} / \mathrm{m} 2$ for men, and $26 \mathrm{~kg} / \mathrm{m} 2$ for women in Asian Indians compared to BMI of $30 \mathrm{~kg} /$ $\mathrm{m} 2$ at an average for Europeans) [19]. This was also deemed due to higher abdominal fat, higher overall fat percentage, lower lean mass, and lower skeletal and bone mineral mass compared to Caucasian and European populations. The Indian Subcontinent population notes much higher prevalence of hypertriglyceridemia, high total cholesterol to high-density lipoprotein (HDL), and central obesity [20]. As such, they are noted to suffer higher cardiovascular morbidity and mortality at a much lower BMI or waist circumference [20]. Nontraditional risk factors that are not included in the conventional risk models are also more prevalent in South Asians. Immigrants from the Indian subcontinent who settled in the US, UK or other European countries were noted to have increased obesity, apolipoprotein B levels, fasting plasma insulin, CRP, serum TG and decreased B cell function compared to the mostly Caucasian population currently living there [21-24]. 


\section{Joint European Society of Cardiology (Joint ESC) Guidelines}

The Joint ESC recommends using SCORE system to establish the 10-year risk of fatal cardiovascular disease [25]. However, the accuracy of this traditional 10-year risk assessment tool is unknown in non-Caucasian populations. Admittedly, "Ethnicity should be considered in CVD risk assessment" is noted as a Class IIa, Level A indication. Joint ESC guidelines acknowledge that South Asians and sub-Saharan Africans are at higher risk of cardiovascular disease, while Chinese and South Americans are at a lower risk as compared to European Caucasian population. SCORE 10-year CVD risk assessment tool does not include diabetes mellitus as part of its risk calculation which may account for its limited usefulness in the South Asian population since other risk factors remain similar but poorer glycemic control has been noted [26-28]. The link of central obesity and increased waist measurement with increased CVD remains firm, with again the caveat that these measurements are based on Caucasian populations.

\section{ETHRISK Calculator}

The ETHRISK calculator uses the Framingham risk score and re-calculates the 10-year CVD risk based on the relatively increased cardiovascular risk burden ethnic minority populations [29]. The study included 8,332 people (3778 men and 4544 women) aged 35-54 from two community-based surveys (England Health Surveys 1998 and 1999, and Wandsworth Heart and Stroke Study). However, the calculator takes into account a small age range to build its risk assessment model, is based on the Framingham risk score which predates the Pooled Cohort Equation risk stratification tool, and most critically, excludes patients with diabetes mellitus suggested to be one of the highest risk factors for cardiovascular risk in this population. As such, while validated in the South Asian population, the use of the calculator provides an underpowered and underestimated cardiovascular risk in the South Asian population, specifically Pakistani, Indian and Bangladeshi ethnic population. And yet none of these markers seems to have a genomic cause based on data from Indian migrants to England. This raises question of a missing causative factor [30].

\section{QRISK 3 (2018) Calculator}

The QRISK3 cardiovascular risk calculator is based on the QRESEARCH database that takes advantage of a large centralized database of 7.89 million people available through the UK National Health Service data from general practices between 1993-2015 [31]. While 88\% of the population in the QRESEARCH database was Caucasian, most critical in this is the subgroup analysis with the presence of a large sample size of South Asian ethnic minorities. This is further separated by gender. Based on the Q-RISK3 data, adjusted hazard ratio's indicate that Indian (Women: 1.32, Men: 1.31), Pakistani (Women: 1.76, Men: 1.61-1.62), Bangladeshi (Women: 1.33-1.35, Men: 1.70) ethnic populations have a significantly higher cardiac risk compared to Caucasians (hazard ratio $=1.0$ ) and even when compared to other Asian population (Women: 1.07-1.08,
Men: 1.03). And yet when applied to a local native population this seemed to elevate overall risk by $50 \%$ as compared to self-reported event rates thrusting doubt upon its actual utility [32].

\section{Opportunity for Further Study}

Traditional risk scoring systems have not been clearly validated in minority populations. Within the U.S., South Asians are a subset who have vastly different risk profiles; younger age, lower BMI than the White Caucasian populations. It is important for clinicians to be aware of the limitations of the widely used risk stratification tools. With the increasing adoption of electronic health records across the country, we have the opportunity to study large numbers of patients over time and validate or create new risk models, for minority populations. Given the worsening epidemic and outcomes in the South Asian population, it is important that public health agencies, funders, researchers, and physicians work on identifying risk factors in this population.

\section{Acknowledgement}

None.

\section{Conflict of Interest}

No conflict of interest.

\section{References}

1. World Health Organization: WHO (2017) Cardiovascular diseases (CVDs).

2. Benjamin EJ, Virani SS, Callaway CW, Chamberlain AM, Chang AR, et al (2018) Heart disease and stroke statistics-2018 update: a report from the American Heart Association. Circulation 137(12): e67-e492.

3. Benjamin EJ, Muntner P, Alonso A, Bittencourt MS, Callaway CW, et al. (2019) Heart disease and stroke statistics-2019 update: a report from the American Heart Association. Circulation 139(10): e56-e528.

4. (2019) CDC Prevention Programs (n.d.).

5. Budiman A (2019) Key facts about Asian origin groups in the U.S.

6. US Census Bureau Public Information Office (2011) 2010 Census Shows America's Diversity - 2010 Census - Newsroom - U.S. Census Bureau.

7. Haniffa A (2019) South Asian population in the U.S. grew by 2 million in 7 years: Survey.

8. (2019) Asian Americans \& Heart Disease - Facts \& Statistics. (n.d.).

9. Arnett DK, Blumenthal RS, Albert MA, Buroker AB, Goldberger ZD, et al. (2019) 2019 ACC/AHA guideline on the primary prevention of cardiovascular disease: executive summary: a report of the American College of Cardiology/American Heart Association Task Force on Clinical Practice Guidelines. Journal of the American College of Cardiology 74(10): 1376-1414.

10. Rodriguez F, Chung S, Blum MR, Coulet A, Basu S, et al. (2019) Atherosclerotic cardiovascular disease risk prediction in disaggregated Asian and Hispanic subgroups using electronic health records. Journal of the American Heart Association 8(14): e011874.

11. Rana JS, Tabada GH, Solomon MD, Lo JC, Jaffe MG, et al. (2016) Accuracy of the atherosclerotic cardiovascular risk equation in a large contemporary, multiethnic population. Journal of the American College of Cardiology 67(18): 2118-2130.

12. DeFilippis AP, Young R, McEvoy JW, Michos ED, Sandfort V, et al. (2017) Risk score overestimation: the impact of individual cardiovascular risk factors and preventive therapies on the performance of the American Heart Association-American College of Cardiology-Atherosclerotic Cardiovascular Disease risk score in a modern multi-ethnic cohort. 
European Heart Journal 38(8): 598-608.

13. Hussain SM, Oldenburg B, Wang Y, Zoungas S, Tonkin AM, et al. (2013) Assessment of cardiovascular disease risk in South Asian populations. International journal of vascular medicine.

14. Cooper A, NO Flynn (2008) Risk assessment and lipid modification for primary and secondary prevention of cardiovascular disease: summary of NICE guidance. Bmj 336(7655): 1246-1248.

15. Ghaffar A, Reddy KS, Singhi M (2004) Burden of non-communicable diseases in South Asia. Bmj 328(7443): 807-810.

16. Enas EA, Garg A, Davidson MA, Nair VM, Huet BA, et al. (1996) Coronary heart disease and its risk factors in first-generation immigrant Asian Indians to the United States of America. Indian heart journal 48(4): 343353.

17. Gupta R (1997) Epidemiological evolution and rise of coronary heart disease in India. South Asian J Prev Cardiol 1(1)

18. Enas EA, Yusuf S (1999) Third Meeting of the International Working Group on Coronary Artery Disease in South Asians. 29 March 1998, Atlanta, USA. Indian heart journal 51(1): 99-103.

19. Rush EC, Freitas I, Plank LD (2009) Body size, body composition and fat distribution: comparative analysis of European, Maori, Pacific Island and Asian Indian adults. British Journal of Nutrition 102(4): 632-641.

20. Nag T, Ghosh A (2013) Cardiovascular disease risk factors in Asian Indian population: a systematic review. Journal of cardiovascular disease research 4(4): 222-228.

21. Bhatnagar D, Anand IS, Durrington PN, Patel DJ, Wander GS, et al. (1995) Coronary risk factors in people from the Indian subcontinent living in west London and their siblings in India. The Lancet 345(8947): 405-409.

22. Patel JV, Vyas A, Cruickshank JK, Prabhakaran D, Hughes E, et al. (2006) Impact of migration on coronary heart disease risk factors: comparison of Gujaratis in Britain and their contemporaries in villages of origin in India. Atherosclerosis 185(2): 297-306.

23. Tennakoon SU, Kumar BN, Nugegoda DB, Meyer HE (2010) Comparison of cardiovascular risk factors between Sri Lankans living in Kandy and Oslo. BMC public health 10(1): 654.
24.Zahid N, Meyer HE, Kumar BN, Claussen B, Hussain A, et al. (2011) High levels of cardiovascular risk factors among Pakistanis in Norway compared to Pakistanis in Pakistan. Journal of obesity.

25. Piepoli MF, Hoes AW, Agewall S, Albus C, Brotons C, et al. (2016) 2016 European Guidelines on cardiovascular disease prevention in clinical practice: The Sixth Joint Task Force of the European Society of Cardiology and Other Societies on Cardiovascular Disease Prevention in Clinical Practice (constituted by representatives of 10 societies and by invited experts) Developed with the special contribution of the European Association for Cardiovascular Prevention \& Rehabilitation (EACPR). European heart journal 37(29): 2315-2381.

26. Bhopal RS, Bansal N, Fischbacher CM, Brown H, Capewell S, et al. (2012) Ethnic variations in the incidence and mortality of stroke in the Scottish Health and Ethnicity Linkage Study of 4.65 million people. European journal of preventive cardiology 19(6): 1503-1508.

27. Tran AT, Straand J, Diep LM, Meyer HE, Birkeland KI, et al. (2011) Cardiovascular disease by diabetes status in five ethnic minority groups compared to ethnic Norwegians. BMC public health 11(1): 554.

28. Bansal N, Fischbacher CM, Bhopal RS, Brown H, Steiner MF, et al. (2013) Myocardial infarction incidence and survival by ethnic group: Scottish Health and Ethnicity Linkage retrospective cohort study. BMJ open 3(9): e003415.

29. Brindle P, May M, Gill P, Cappuccio F, D Agostino R, et al. (2006) Primary prevention of cardiovascular disease: a web-based risk score for seven British black and minority ethnic groups. Heart 92(11): 1595-1602.

30. Palaniappan L, Wang Y, Fortmann SP (2004) Coronary heart disease mortality for six ethnic groups in California, 1990-2000. Annals of epidemiology 14(7): 499-506.

31. Hippisley-Cox J, Coupland C, Brindle P (2017) Development and validation of QRISK3 risk prediction algorithms to estimate future risk of cardiovascular disease: prospective cohort study. bmj 357: j2099.

32. Tan ST, Scott W, Panoulas V, Sehmi J, Zhang W, et al. (2014) Coronary heart disease in Indian Asians. Global Cardiology Science and Practice. 